\title{
Sistem Informasi Manajemen Data Showroom Berbasis Multi User
}

\author{
Sofiansyah Fadli ${ }^{1}$, Khairul Imtihan ${ }^{2}$ \\ 1,2Teknik Informatika, STMIK LOMBOK \\ Jl. Basuki Rahmat No.105 Praya Lombok Tengah, Nusa Tenggara Barat 83511 \\ sofiansyah182@gmail.com ${ }^{\text {, khairulimtihan31@gmail.com² }}$
}

\begin{abstract}
Abstrak - Untuk dapat menjaga kelangsungan usaha showroom, maka perlu adanya pencatatan sistem penjualan yang harus dirancang sedemikian rupa untuk mempermudah jalannya proses bisnis showroom berjalan. Tujuan dari penelitian ini adalah mengembangkan Sistem informasi manajemen data showroom berbasis multi user yang bersifat komputerisasi. Dengan adanya sistem ini pengolahan data dan informasi menjadi lebih terdata dan tersimpan pada database diaplikasi, hal ini berdampak pada perubahan sistem yang lebih baik dari sistem yang ada sebelumnya. Informasi manajemen data showroom berbasis multi user pada sebuah showroom adalah aplikasi yang menangani jual beli motor bekas. Pengolahan data ini meliputi data pembelian, data penjualan, dan transaksi pembayaran secara tunai. Dalam aplikasi ini juga terdapat pendataan yang diperlukan dalam sistem jual beli motor yaitu pendataan pegawai, pendataan customer dan pendataan barang. Aplikasi ini dikembangkan dengan menggunakan bahasa pemrograman Delphi dengan menggunakan MySQL sebagai databasenya.
\end{abstract}

Kata kunci: Sistem Informasi, Analisis Sistem, Berbasis Multi User.

\section{PENDAHULUAN}

Seiring dengan perkembangan teknologi yang semakin pesat, perkembangan kegiatan perdagangan juga mengalami peningkatan yang cukup pesat dan luas. Hal ini menyebabkan informasi yang cepat dan akurat menjadi sumber daya yang sangat penting. Oleh karena itu, komputer sebagai perangkat pengolah data dan informasi memegang peranan yang cukup penting. Penggunaan sistem yang terkomputerisasi bukan lagi merupakan hal yang baru, namun telah menjadi sistem pokok untuk dapat bertahan dan berkembang menghadapi tantangan perdagangan bebas pada tahun yang akan datang.

Mengingat pesatnya kemajuan dibidang teknologi informasi dan banyaknya pesaing, maka kegiatan pencatatan sistem penjualan merupakan bagian utama dan penting dalam kegiatan operasional pada showroom. Untuk dapat menjaga kelangsungan usaha showroom, maka perlu adanya pencatatan sistem penjualan yang harus dirancang sedemikian rupa untuk mempermudah jalannya proses bisnis showroom. Dunia bisnis yang bersifat dinamis, cepat serta penuh ketidakpastian menuntut agar dapat membantu sistem penjualan yang lebih terkomputerisasi guna mempermudah cara kerja pada showroom tersebut.

Dengan adanya pembuatan sistem ini, diharapkan dapat membantu cara kerja showroom dan dapat mempersingkat waktu dengan menjalankan proses bisnis yang lebih baik, serta dapat menyajikan data yang lebih akurat dan cepat sehingga dapat menganalisis dan mengevaluasi sistem penjualan dengan efektif dan efisien.

\section{METODE PENELITIAN}

\section{A. Pengumpulan Data}

Observasi, penulis melakukan observasi untuk mengamati dan mencatat prosedur dalam manajemen data showroom yang meliputi : transaksi pembelian sepeda motor, transaksi penjualan tunai, persediaan barangdan pembuatan laporan.

Selain observasi, penulis melakukan wawancara dengan cara mengajukan pertanyaan-pertanyaan atau wawancara langsung kepada pihak manajemen showroom, diantaranya : pemilik, staff maupun pegawai untuk memahami prosedur mengenai bagaimana sistem informasi manajemen data showroom

Untuk mendapatkan data yang lebih tepat dan akurat dalam penulisan proyek tugas akhir ini, penulis juga menambahkan referensi dari berbagai sumber diantaranya : buku, modul, internet dan sumber lain yang berkaitan dengan manajemen data showroom yang penulis susun.

Dokumentasi, pengumpulan data berupa sumber atau berkas yang berhubungan dengan pengolahan data showroom untuk mendorong keakuratan data yang akan diperlukan, diantaranya : data pembelian sepeda motor, data penjualan secara tunai, dan transaksi pembayaran secara tunai.

\section{B. Metode Pengembangan Sistem}

Metode yang digunakan untuk pengembangan sistem adalah metode waterfall. Waterfall adalah model klasik yang bersifat sistematis, berurutan dalam membangun software [6]. 


\section{Analisis dan Perancangan Sistem}

Pada bagian ini akan dilakukan analisis secara mendalam pada sistem yang akan digunakan secara menyeluruh ke dalam bagian-bagian dari komponen sistem dengan maksud agar dapat diketahui permasalahan, kesempatan, hambatan dan kebutuhan yang diperlukan sehingga dapat dilakukan perbaikan pada tahap analisis sebuah sistem dan dapat mencapai tujuan dari pembangunan sistem. Secara global analisis sistem adalah mengidentifikasi apapun yang diperlukan oleh sistem yang akan dibangun dan memahami dengan jelas proses yang akan berjalan pada sistem.

\section{Perancangan Sistem}

Perancangan sistem merupakan tahapan pengembangan perangkat lunak yang dilakukan setelah tahapan analisis. Hasil analisis dijadikan dasar untuk merancang pengembangan perangkat lunak sehingga perangkat lunak yang dihasilkan dapat memenuhi kebutuhan pengguna. Perancangan sistem akan memberikan gambaran rinci mengenai sistem yang akan dibangun dengan menggunakan Context Diagram, Data Flow Diagram, Entity Relationship Diagram, Table Relationship, Perancangan antarmuka (interface) dan spesifikasi dokumen yang digunakan.

\section{E. Entity Relationship Diagram (ERD)}

Entity Relationship Diagram merupakan jaringan yang menggunakan suatu data yang disimpan dari sistem secara abstrak. pada dasarnya adalah diagram yang memperlihatkan entitas-entitas yang terlibat dalam suatu sistem yang bertujuan untuk menunjukan objek data relationship yang ada pada objek tersebut.

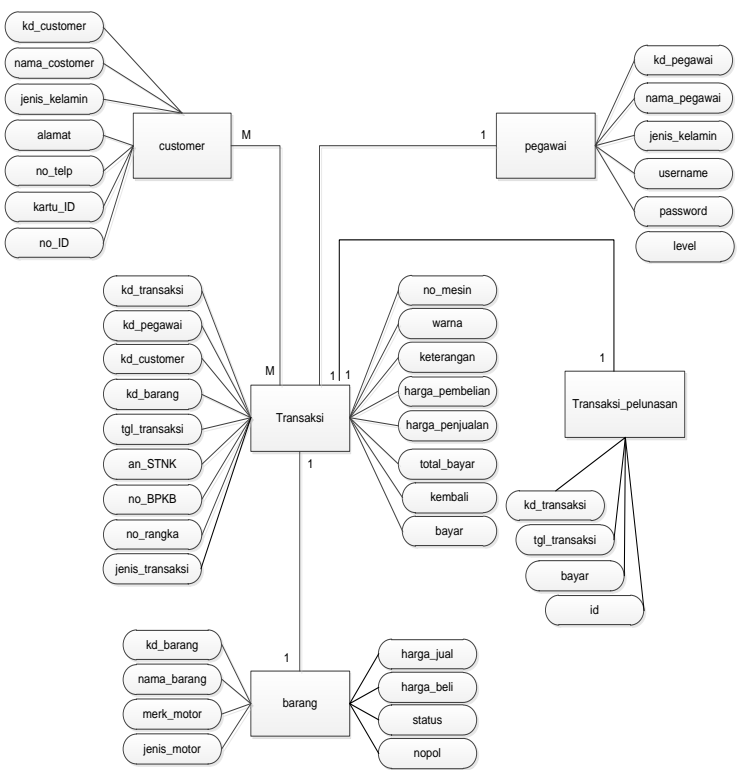

Gambar 1. Entity Relationship Diagram
F. Diagram Konteks

Diagram konteks digunakan untuk memperjelas proses kerja dari sistem yang akan dibuat. Diagram konteks selalu mengandung satu daya dan hanya satu proses saja. Proses ini mewakili dari proses seluruh sistem. Diagram konteks ini menggambarkan hubungan input / output antara sistem dengan dunia luar.

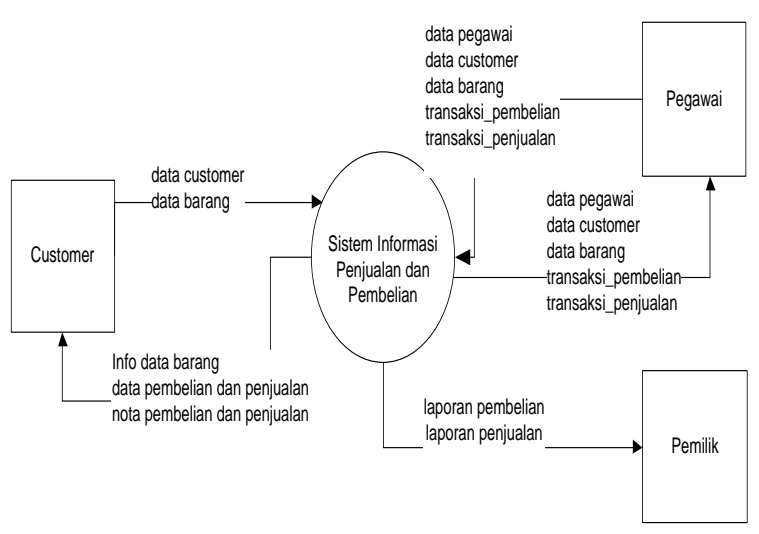

Gambar 2. Diagram Konteks

G. Data Flow Diagram (DFD) Level 1

DFD level 1 merupakan diagram yang menjelaskan sistem menjadi bagian yang lebih kecil dari masing-masing proses pengolahan data yang ada di dalam diagram.

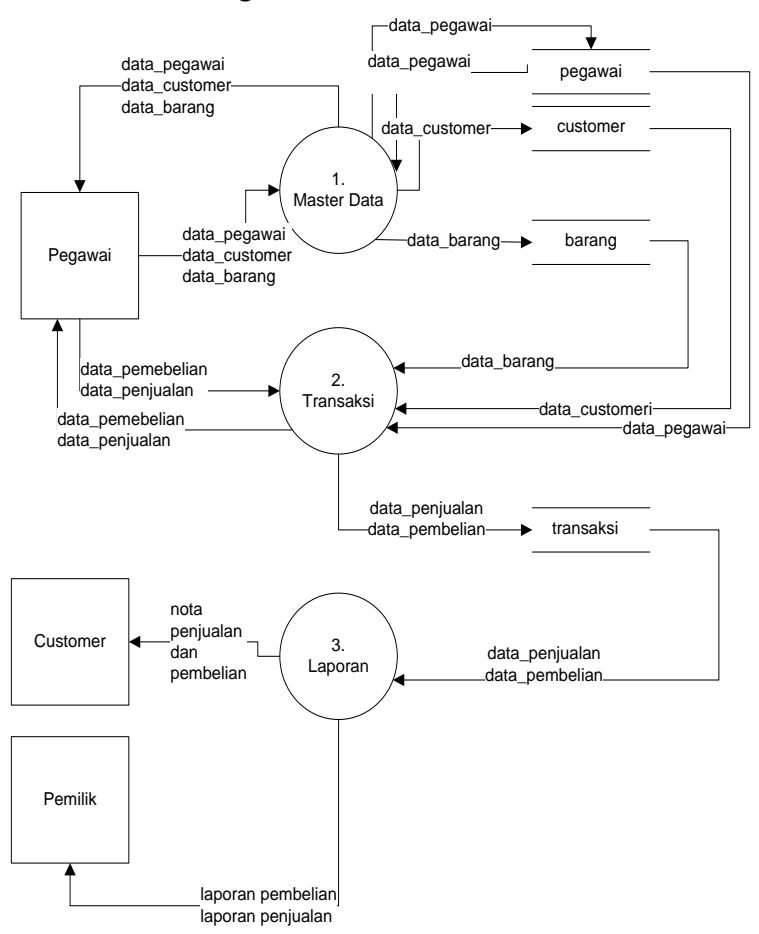

Gambar 3. Data Flow Diagram (DFD) Level 1 


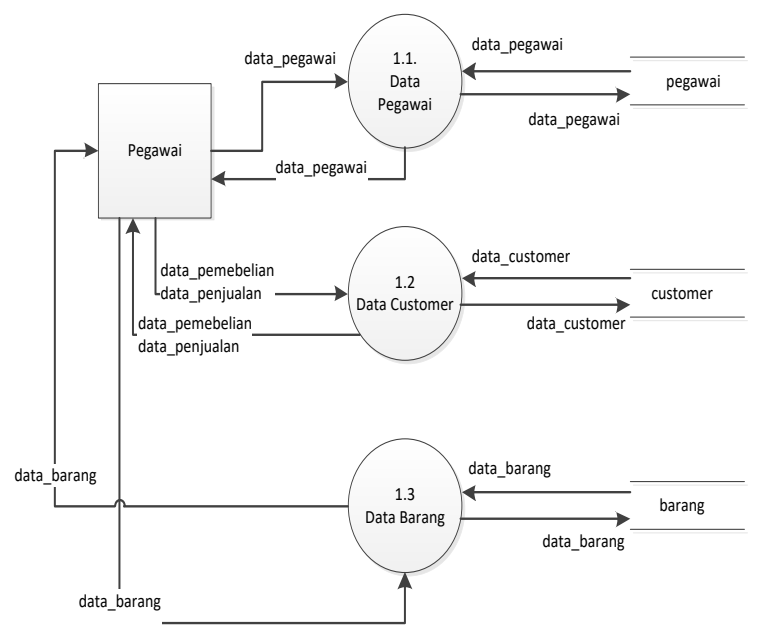

Gambar 4. DFD Level 2 Proses 1

I. Data Flow Diagram (DFD) Level 2 Proses 2

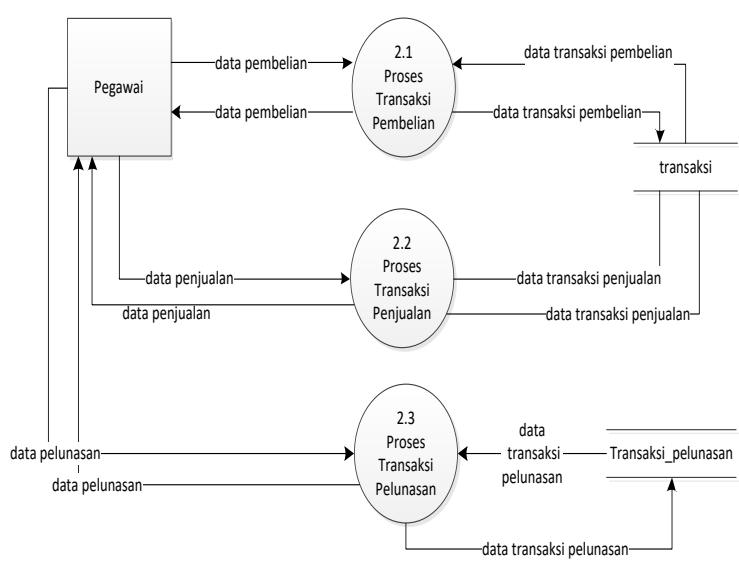

Gambar 5. DFD Level 2 Proses 2

J. Data Flow Diagram (DFD) Level 2 Proses 3

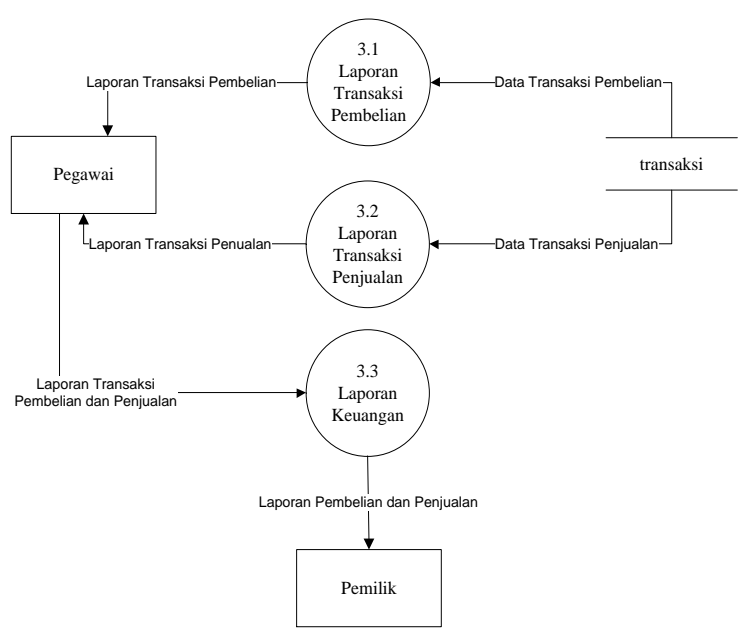

Gambar 6. DFD Level 2 Proses 3

\section{A. Implementasi Sistem}

Sistem informasi manajemen data showroom berbasis multi user merupakan sebuah aplikasi perangkat lunak komputer yang dibangun dan dikembangkan untuk memudahkan showroom dan para user yang terlibat didalam sistem untuk melakukan pengolahan data transaksi pembelian dan penjualan, pencatatan dan laporan. Aplikasi ini menggunakan menu file, input, proses dan laporan sesuai dengan prosedur masukan dalam perancangan sistem pada bab sebelumnya, sehingga alur program akan mengikuti alur jalannya pengambaran diagram sistem.

Dalam implementasi ini menampilkan tentang hasil program di mana tampilan aplikasi sesuai dengan aslinya yang nantinya akan digunakan oleh showroom dalam menjalankan program.

\section{B. Menu Utama}

Halaman ini berfungsi sebagai halaman induk dari sistem informasi manajemen data showroom berbasis multi user, dimana semua perintah pemanggilan halaman terdapat pada menu halaman utama. Saat pertama kali program di jalankan, kita akan diarahkan terlebih dahulu ke menu login, dengan mengisi username dan password dengan benar maka akan masuk ke dalam program dengan menu lengkap yang telah tersedia di dalam program ini.

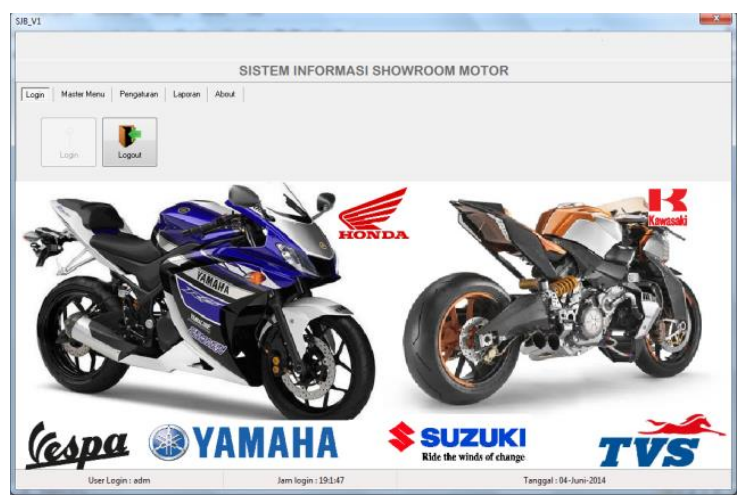

Gambar 7. Tampilan Form Menu Utama

\section{Form Master Data Customer}

Pada form master data customer terdapat tombol tambah yang berfungsi untuk menambah data customer, tombol simpan untuk menyimpan data customer, tombol ubah untuk mengubah data customer, tombol hapus untuk menghapus data customer. 


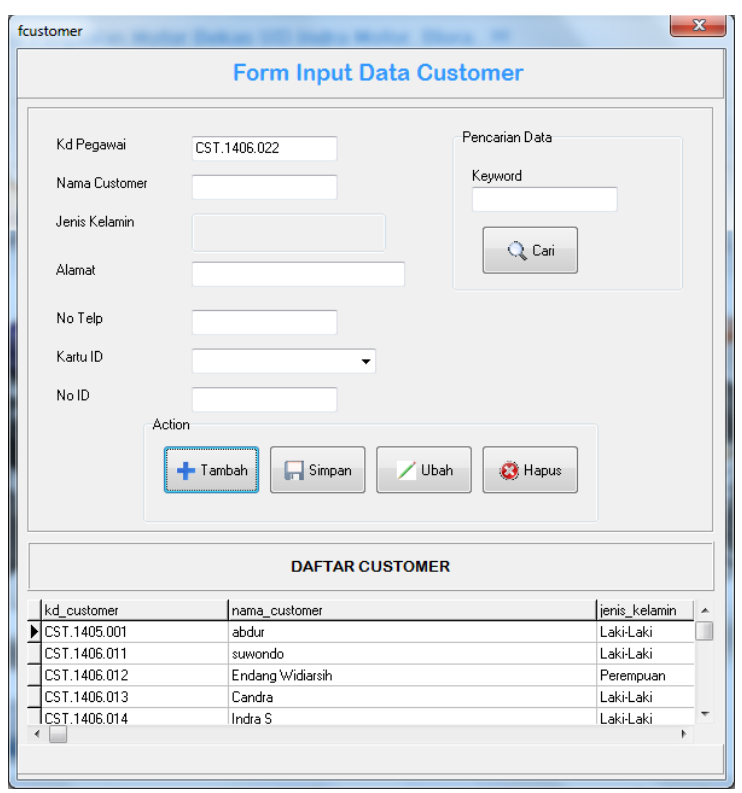

Gambar 8. Form Master Data Custemer

\section{Form Master Data Pegawai}

Pada form master data pegawai terdapat tombol tambah yang berfungsi untuk menambah data pegawai, tombol simpan untuk menyimpan data pegawai, tombol ubah untuk mengubah data pegawai, tombol hapus untuk menghapus data pegawai.

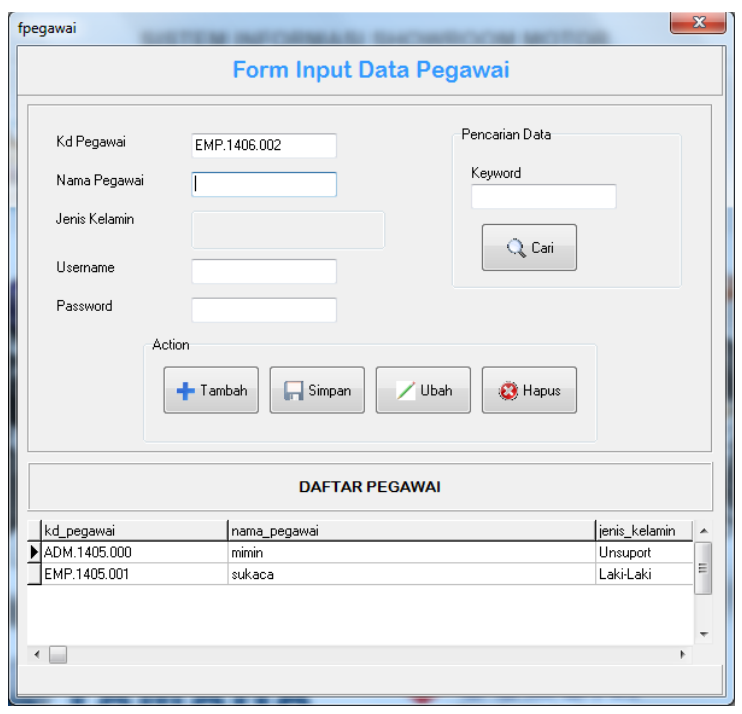

Gambar 8. Form Master Data Pegawai

\section{E. Form Master Data Barang}

Pada form master data barang ini berfungsi untuk menampilkan data barang yang ada pada showroom, terdapat tombol cari yaitu, untuk mencari data barang.

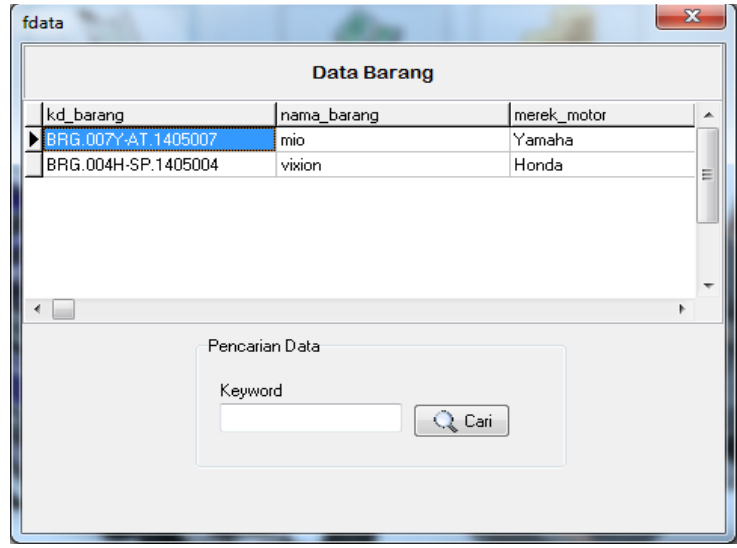

Gambar 10. Form Master Data Barang

F. Form Proses Transaksi Pembelian

Form transaksi pembelian ini akan menampilkan form transaksi pembelian, dimana user akan menginputkan semua proses pembelian sepeda motor bekas. Terdapat tiga tombol yaitu, tombol tambah untuk menambahkan semua transaksi pembelian sepeda motor bekas, tombol simpan untuk menyimpan transaksi pembelian, dan tombol hapus untuk menghapus transaksi pembelian sepeda motor bekas.

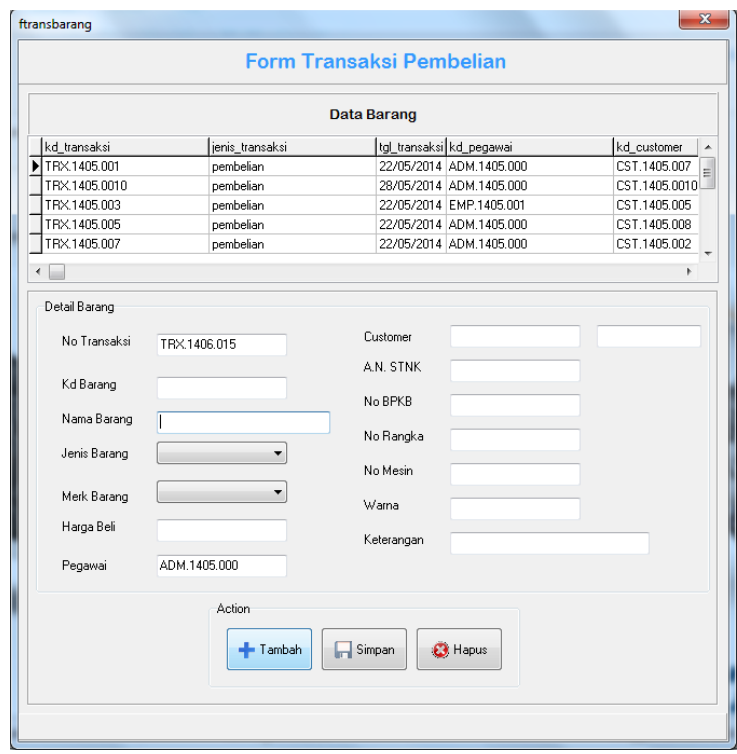

Gambar 11. Form transaksi pembelian

G. Form Proses Transaksi Penjualan

Form transaksi penjualan ini akan menampilkan form transaksi penjualan, dimana user akan menginputkan semua proses pejualan sepeda motor bekas. Terdapat tiga tombol yaitu, tombol tambah untuk menambahkan semua transaksi penjualan sepeda motor bekas, tombol simpan untuk menyimpan transaksi penjualan, dan tombol hapus untuk menghapus transaksi penjualan sepeda motor bekas. 


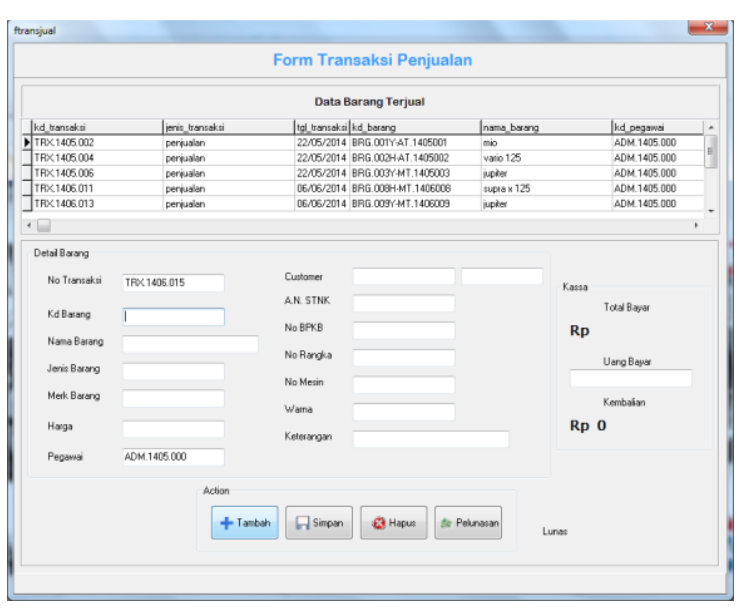

Gambar 12. Form Transaksi Penjualan

\section{H. Form Proses Transaksi Pelunasan}

Form transaksi pelunasan ini akan menampilkan transaksi pelunasan, user akan menginputkan semua proses transaksi barang yang belum lunas. Terdapat dua tombol yaitu, tombol cari untuk menncari data barang yang belum lunas, dan tombol bayar untuk membayar kekurangan pada pembelian sepeda motor bekas.

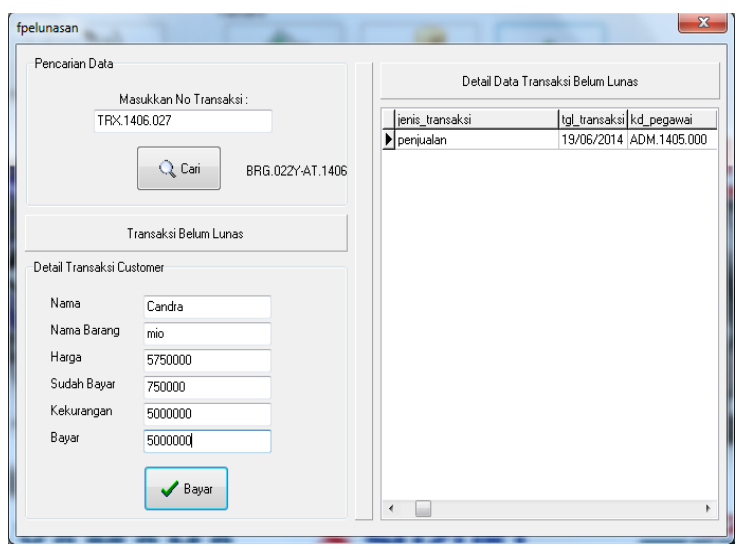

Gambar 13. Form Transaksi Pelunasan

\section{KESIMPULAN DAN SARAN}

\section{A. Kesimpulan}

Berdasarkan hasil dari penelitian yang telah dilakukan, maka dapat diambil kesimpulan bahwa: sistem informasi manajemen data showroom berbasis multi user dirancang untuk mempermudah dan mempercepat dalam proses transaksi jual beli sepeda motor bekas. Penggunaan pencarian dalam transaksi dapat mempermudah dalam pencarian data transaksi jual beli sepeda motor bekas. Dengan mengimplementasikan sistem ini dapat menjadi solusi dan alternatif dalam permasalahan yang sering terjadi seperti pencatatan data dan transaksi secara manual yang sering menimbulkan masalah. Dengan adanya aplikasi ini akan memudahkan bagi user untuk mengakses data customer, data pegawai, data barang, data transaksi pembelian dan data transaksi penjualan.

\section{B. Saran}

Dari uraian sistem informasi manajemen data showroom berbasis multi user, penyusun menyarankan agar: Sistem Informasi Manajemen Data Showroom Berbasis Multi User ini sebaiknya ditambah fasilitas back-up data setiap bulan untuk menjaga keamanan sebagai cadangan apabila terjadi masalah atau kerusakan pada media penyimpanan. Perencanaan sistem informasi yang baru harus dibuat fleksibel, agar dapat menghadapi perubahan yang terjadi, sehingga tidak memerlukan banyak waktu dan perubahan yang harus dilakukan.

\section{REFERENSI}

[1] Fadli, Sofiansyah. 2018. Model Rapid Application Development Dalam Pengembangan Sistem Reservasi dan Penyewaan Kamar Hotel. Jurnal Informatika dan Rekayasa Elektronik. Volume 1, No 1.

[2] Kendall, K dan Julie E. Kendall. 2003. Analisa dan Perancangan Sistem. Edisi Bahasa Indonesia. Pt. Prenhallindo. Jakarta.

[3] Kristanto, Andry. 2003. Perancangan Sistem Informasi dan Aplikasi. Graha Ilmu. Yogyakarta

[4] McLeod Jr., Raymond 2004. Tuyas A \& M University. Jilid I. Sistem Informasi Manajemen Studi Sistem Informasi Berbasis Komputer. PT. Prenhallindo. Jakarta

[5] Medianto, Singgih. 2012, Aplikasi Penjualan Sepeda Motor Bekas Pada Barokah Arga, Management Informatika dan Komputer, Amikom, Yogyakarta.

[6] Pressman, Roger S., 2002. Rekayasa Perangkat Lunak : Pendekatan Praktisi (Buku I). Andi Offset. Yogyakarta.

[7] Ulfah, N.A. 2011. Sistem Informasi Pengolahan Data Penjualan Spare Part Sepeda Motor Pada Showroom Suzuki Batusangkar. Padang: STIMIK Indonesia Padang. 